\section{South African transplantation - where are we now and where should we go next?}

To the Editor: South Africa has a huge potential for organ transplantation. Deceased donation is well established, and we are one of the few African countries with brain death legislation. However, despite adequate legislation and well-established transplant units, donor numbers are decreasing and in some areas living donation now outnumbers deceased donation. Saudi Arabia has set an excellent example in utilising deceased donors and is a role model for other Muslim countries in the Middle East and Africa. In a few years they have built up a deceased donation programme and donor numbers are increasing yearly. ${ }^{1}$

South Africa should strive to provide transplantation leadership and support in the developing world. This requires renewed efforts in obtaining and utilising organ donors. Donation after cardiac death is limited to Groote Schuur Hospital. Consent rates for this type of organ donation are higher in underdeveloped countries, as reflected in increased consent rates at Groote Schuur Hospital. This programme has huge potential, especially in state-sector hospitals where resources to treat head-injured patients are limited.

Factors inhibiting deceased donation from growing in South Africa are religious and social issues, lack of government support (variable organisational systems and variable infrastructure), inappropriate allocation of resources, and a lack of active effort by transplant co-ordinators and doctors in this field. Further obstacles in South Africa are inadequate disease prevention programmes, lack of awareness about brain death diagnosis among health care workers, and lack of funding. Despite a low average income rate in Iran, living and deceased donation is taking place and deceased donation increases yearly. ${ }^{2}$

In most countries where commercial transplantation took place it had a huge impact on organ transplantation. Deceased donation rates fell dramatically and transplantation for the local population decreased. This is not currently taking place in South Africa, probably because of huge efforts by the Transplantation Society and the Istanbul Declaration Custodian Group. ${ }^{3}$ This continuing worldwide problem warrants constant attention.

Liver transplantation in South Africa is limited to deceased donor liver transplantation. Turkey, Egypt and Iran have active living related liver transplantation programmes, and most transplants are done for paediatric recipients. There is no living related liver transplant programme in South Africa, despite a favourable recipient pool at Red Cross War Memorial Children's Hospital.

South Africa must compare itself to other developing countries regarding organ donation and transplantation. We cannot compete with the developed world in terms of infrastructure, support and funding. However, transplant surgeons and physicians must renew efforts to establish and preserve these programmes in the state and private sectors. It is important that continuous efforts be made to increase our deceased donation rates to serve the population awaiting organs.

\section{Elmi Muller}

Groote Schuur Hospital

Cape Town

elmi.muller@uct.ac.za

1. Atter B, Shaheen F, Souqiyyeh MZ, et al. The experience of expanded criteria donors in kidney transplantation in Saudi Arabia: 2008-9. Oral presentation, MESOT congress, Tunisia, 18-21 October 2010.

2. Ghornai F, Vishteh HRK, Shafaghi S, et al. Brain death training for hospital workers increase donor detection rate. Oral presentation, MESOT congress, Tunisia, 18-21 October 2010.

3. The Declaration of Istanbul on Organ Trafficking and Transplant Tourism. http://www. 3. The Declaration of Istanbul on Organ Trafficki
declarationofistanbul.org/ (accessed 7 December 2010).

\section{Reflections on then and now}

To the Editor: I am a former UCT Medical School graduate (1958) who spent a good deal of last year as an inpatient in the UK. This has highlighted for me the changes that have taken place in the intervening years - not the medical advances, but the social ones. I was one of about ten female medical students, a very different ratio to that which obtains today. Then propriety dictated that women and men had to have separate dissecting rooms for anatomy. One wonders what moral turpitude was feared should we have shared the same facilities. Obstetric practice was also taught in single-sex groups!

Female consultants were then very rare. Helen Brown was an outstanding physician and Pat Massey a highly competent obstetrician/ gynaecologist. Golda Seltzer was very active in pathology. All were rare but very valuable role models.

I was intern to Helen Brown, for whom I developed the greatest respect and affection. She was an excellent physician, and although she had high expectations of her juniors she was very good to work for. I remember that when the firm was overstretched by the need to 'special' a man from what was then Northern Rhodesia and who had severe cerebral malaria, she came in at 2 a.m. to do her stint. I also recall an occasion when she found me upset and near to tears after a failed attempt to save the life of a patient. She took to task a nurse who had been critical of my emotion, saying that it was all right for Dr Robertson to be upset, and that you are in trouble when you stop feeling that way; perhaps an overstatement, but in many ways very true.

As students beginning our fourth year and new to clinical medicine we were required by our consultant tutors to work up the case of our particular assigned patient. My first was a pleasant man with severe emphysema, whom I described as 'elderly'. My tutor, Louis Vogelpoel, commented that ' 55 is not elderly'. At 74 I have long agreed.

I remain most grateful for my years at Groote Schuur Hospital and wish the present trainees as rewarding a career as was opened up for me.

\section{Meg Robertson}

michaelforth@hotmail.com 